\title{
CAPITALISMO, CRISE ECONÔMICA E A PRESERVAÇÃO DOS DIREITOS FUNDAMENTAIS DOS TRABALHADORES NAS TRANSFORMAÇÕES OCORRIDAS NO MERCADO DE TRABALHO, EM ESPECIAL, A PROPALADA REFORMA TRABALHISTA
}

\author{
CAPITALISM, THE ECONOMIC CRISIS AND THE \\ PRESERVATION OF FUNDAMENTAL RIGHTS OF WORKERS \\ DURING THE CHANGES THAT OCCURRED IN THE LABOR \\ MARKET, IN PARTICULAR, THE VAUNTED REFORM LABOR
}

PATRÍCIA DITTRICH FERREIRA DINIZ ${ }^{1}$

MARCO ANTÔNIO CÉSAR VILLATORE ${ }^{2}$

\begin{abstract}
RESUMO: As crises econômicas fazem parte do sistema capitalista, pois é exatamente neste momento que este se move, reinventa-se e traz a transformação necessária para a sua própria manutenção. Normalmente, as mutações estão relacionadas com os elementos essenciais desse sistema, quais sejam, a existência do trabalhador livre assalariado, a propriedade privada, o mercado de trabalho, o mercado para a troca de produtos visando ao lucro e a criação de necessidades simbólicas. A globalização intencionalmente criada foi um exemplo desta mudança, pois tinha o intuito de diminuir a força dos trabalhadores, o seu poder
\end{abstract}

\footnotetext{
Artigo recebido em 15.02.2013. Pareceres emitidos em 03.06.2013, 14.10.2013 e 10.11.2013.

Artigo aceito para publicação em 22.12.2013.

${ }^{1}$ Advogada, Membro da Comissão de Assédio Moral e Conselho de Orientação e Ética, todos na Companhia Paranaense de Energia (COPEL), Especialista em Direito Tributário e Direito do Trabalho, Mestranda em Direito Econômico e Socioambiental, ambos na Pontifícia Universidade Católica do Paraná (PUCPR). Membro do Grupo de Pesquisa "Desregulamentação do Direito, do Estado e Atividade Econômica: Enfoque Laboral". patridf@yahoo.com.br

${ }^{2}$ Pós-Doutorando em Direito pela Universidade de Roma II (UNIROMA II - Tor Vergata), Doutor pela Universidade de Roma I (UNIROMA I - La Sapienza), revalidado pela Universidade Federal de Santa Catarina (UFSC) e Mestre pela Pontifícia Universidade Católica de São Paulo (PUC/SP). Professor Adjunto concursado da Universidade Federal de Santa Catarina (UFSC) e da Faculdade Internacional de Curitiba (FACINTER). Professor Titular do Curso de Mestrado e do Doutorado em Direito da Pontifícia Universidade Católica do Paraná (PUCPR). Líder do Grupo de Pesquisa "Desregulamentação do Direito, do Estado e Atividade Econômica: Enfoque Laboral". Advogado (disponível em http://www.villatore.com.br).marcovillatore@gmail.com
} 
de negociação e até mesmo diminuir os seus salários, visando sempre ao aumento de lucro e à manutenção do sistema. A propalada reforma trabalhista é mais um capítulo desta transformação, mas somente pode ser concretizada através de uma visão desenvolvimentista sustentável, com fundamento nos princípios da proteção e na preservação dos direitos fundamentais dos trabalhadores, porquanto somente assim se poderá falar em um desenvolvimento efetivo. Para este trabalho não permanecer apenas no plano teórico, apresentam-se pontos da reforma trabalhista na Itália realizada através da Lei no 92/2012 determinantes em alterações do Estatuto dos Trabalhadores, em especial, na extinção do contrato de trabalho, retratação da dispensa, complementação salarial e no ASpl - Seguro Social para o Emprego -, exemplo prático que demonstra a necessidade e a importância de determinadas reformas, principalmente, quando se pretende estender benefícios, mesmo que menores, para o maior números de pessoas.

PALAVRAS-CHAVE: Capitalismo; Crise Econômica; Reforma Trabalhista; Direitos Fundamentais; Princípio da Proteção; Direito Comparado.

ABSTRACT: Economic crises are part of the capitalism system, because it is in this exactly moment that it moves, reinvents itself and brings the necessary transformation for its own maintenance. Usually the changes are related to the essential elements of this system, specifically, the existence of paid free workers, private property, labor market, the exchanging market that seeks for profit and symbolic needs. The intentionally created globalization is an example of this transformation, cause it had the aim of reduce the strength of workers, their bargaining power and even to decrease their wages, seeking always for increasing profits and the system maintenance. The disseminated labor reform is another chapter of this transformation, but it only can be achieved through a sustainable developmental view, based on the principles of protection and preservation of the workers' fundamental rights, because only then it will be possible to speak in effective development. Therefore, so that the present paper does not remain only at the theoretical level, it will be presented points of labor reform in Italy, conducted by Law $n^{\circ} 92 / 2012$, which resulted in changes to the workers' statute, in particular, the employment contract extinction, recant of the exoneration, salary supplementation and ASpl - Social Security for Emplyment-, this a practical example that demonstrates the need and importance of certain reforms, especially when the intend is to extend benefits, even small ones, for a larger number of people.

KEYWORDS: Capitalism; Economic Crisis; Labor Reform; Fundamental Rights; Principle of Protection; Comparative Law.

SUMÁRIO: Introdução; 1. Capitalismo, Crise Econômica e Transformação; 2. Desenvolvimento Sustentável, Reforma Trabalhista, Princípio da Proteção e Eficácia dos Direitos Fundamentais dos Trabalhadores; 3. Reforma Trabalhista na Itália e um Comparativo com o Ordenamento Jurídico Brasileiro; Considerações Finais; Referências Bibliográficas.

SUMMARY: Introduction; 1. Capitalism, Economic Crisis and Transformation; 2. Sustainable Development, Labor Reform, Principle of Protection and Effectiveness of Fundamental Worker's Rights; 3. Labor Reform in Italy and Comparison with the Brazilian Legal System; Final Considerations; Bibliographical References. 


\section{INTRODUÇÃO}

O capitalismo se move e se reinventa a partir da existência de crises econômicas, que nada mais são do que oscilações na economia, e, após cada crise, caminha novamente e tenta encontrar uma nova direção, ou apenas uma maneira diferente de caminhar no mesmo rumo.

Viver fora do sistema capitalista é praticamente inimaginável, portanto, é preciso encontrar uma forma de continuar o desenvolvimento do sistema de forma sustentável, equilibrando os aspectos econômicos, sociais e ambientais.

É exatamente esta a preocupação do presente artigo: analisar as transformações ocorridas e sugeridas pelos doutrinadores para o mercado de trabalho, como a flexibilização, desregulamentação e reformas trabalhistas, tudo em conjunto com o princípio da proteção, e inferir qual o melhor método para alavancar a economia e preservar os direitos fundamentais dos trabalhadores de forma equilibrada.

Para tanto, apresentar-se-á um estudo acerca do capitalismo, da crise econômica e da transformação da sociedade, e, após, adentrar-se-á no tema do desenvolvimento sustentável, da reforma trabalhista, do princípio da proteção e da eficácia dos direitos fundamentais dos trabalhadores.

Por fim, serão expostos os principais pontos da reforma trabalhista, na Itália, ocorrida no ano de 2012, no que se refere às dispensas, renúncia em branco e resoluções do contrato de trabalho, além do ASpl - Seguro Social para o Emprego -, entre outras modificações, sendo apresentado um pequeno comparativo com o ordenamento jurídico brasileiro.

\section{CAPITALISMO, CRISE ECONÔMICA E TRANSFORMAÇÃO}

Max Weber tinha uma grande preocupação em explicar a origem do capitalismo moderno ${ }^{3}$, não no seu sentido histórico ou de formação, mas no de encontrar o nascimento do espírito do capitalismo, da mentalidade fomentadora de tal sistema, do ethos.

O autor encontra essa resposta na religião protestante, eis que de um ponto de partida empírico observou que a maioria dos agentes decisivos nos negócios, ou seja, com comportamento capitalista, eram advindos da mencionada religião, pois possuíam a vocação profissional, conforme professava Lutero ${ }^{4}$, ou seja, aceitavam os desígnios de Deus e trabalhavam e viviam

\footnotetext{
${ }^{3}$ O "capitalismo" existiu anteriormente na China, na Índia, na Babilônia, na Antiguidade e na Idade Média, mas não com esse espírito do capitalismo moderno. In WEBER, Max. A Ética Protestante e o "espírito" do Capitalismo. Tradução: José Marcos Mariani de Macedo. São Paulo: Companhia das Letras, 2004, p. 45.

${ }^{4}$ Há que se ter cuidado em relacionar Lutero diretamente com o capitalismo, eis que a vocação profissional por ele professada pode ter diversas interpretações, e não é demais ressaltar que ele próprio fez inúmeras declarações contra a usura e a cobrança de juros em geral, o que demonstra uma visão retrógrada para um pensamento capitalista. In WEBER, Max. A Ética Protestante e o "espírito" do Capitalismo. Tradução: José Marcos Mariani de Macedo. São Paulo: Companhia das Letras, 2004, p. 74.
} 
do suor do seu trabalho, do que nasce a compulsão para o ativismo, seja empresarial ou laborioso, impulsionado pela transformação e erguimento de novas estruturas, inclusive com o advento da competição entre os feitos de cada indivíduo. ${ }^{5}$

Everett Hagen afirmava que o espírito do capitalismo surgia da mente de pessoas com personalidades modernas, geradoras de mudança, inovações e mais adaptáveis às transformações sociais e, em contrapartida, existiam as pessoas com personalidade tradicional, reconhecidas por seu modo autoritário, estagnado, de simples reprodução e apreciadoras do equilíbrio. $^{6}$

Independente do estudo do surgimento do espírito capitalista, não há como negar ou tergiversar acerca da existência de tal sistema. Marx já afirmava que o capitalismo é uma falha metabólica, ocasionando a degradação ambiental do trabalhador e o desenvolvimento da raça humana, uma vez que "perturba a interação metabólica entre o homem e a terra, isto é impede a devolução ao solo dos seus elementos constituintes" e "prejudica a operação da condição natural eterna para a fertilidade duradoura do solo".

A existência de trabalhador livre e assalariado é um dos requisitos essenciais para a formação e a continuidade do capitalismo, e para obter tal intento, ocorreu a expropriação do trabalhador em maior número, no momento de transição do período feudalista para o capitalista. ${ }^{8}$

Tal expropriação consistia em retirar os instrumentos de trabalho do pequeno proprietário/camponês, quais sejam, a terra, as ferramentas e as máquinas, pois assim ele não teria mais como produzir para o seu próprio sustento, e, em contrapartida, era obrigado a trabalhar para os possuidores dos bens de produção e ainda consumir no mercado interno, criando então outro requisito essencial para a manutenção do capitalismo. ${ }^{9}$

Para manter essa mão de obra de forma regular e constante, o Estado impôs um preço para a terra tão alto que impedia a esses trabalhadores de realizarem tal aquisição e retornarem ao seu status de camponês, e, se não impedia, ao menos atrasava o seu intento, até que nova mão de obra estivesse disponível, mantendo dessa forma o capitalismo funcionando sem maiores problemas. ${ }^{10}$

\footnotetext{
${ }^{5}$ WEBER, Max. A Ética Protestante e o "espírito" do Capitalismo. Tradução: José Marcos Mariani de Macedo. São Paulo: Companhia das Letras, 2004, p. 41-85.

6 SZTOMPKA, Piotr. A Sociologia da Mudança Social. Tradução Pedro Jorgensen Jr. Rio de Janeiro: Civilização Brasileira, 1989, p. 404-407.

${ }^{7}$ FOSTER, John Bellamy. O Conceito de Natureza em Marx: materialismo e natureza. 3. ed., Rio de Janeiro: Civilização Brasileira, 2005. p. 219.

${ }^{8}$ MARX, Karl. O Capital: crítica da economia política. Livro primeiro. São Paulo: Abril Cultural, 1984. p. 383-392.

${ }^{9}$ Ibidem, p. 383-392.

${ }^{10}$ Ibidem, p. 383-392.
} 
Dessa forma, "o modo capitalista de produção e acumulação e, portanto, a propriedade privada capitalista exigem o aniquilamento da propriedade privada baseada no trabalho próprio, isto é, a expropriação do trabalhador". ${ }^{11}$

Com a referida expropriação, houve uma transferência de propriedade do patrimônio dos pequenos produtores para a classe burguesa, começando a acumulação primitiva, ponto de partida do capitalismo, bem como ocorreu a divisão entre os possuidores dos bens de produção e a força de trabalho. ${ }^{12}$

A propriedade privada e o mercado de trabalho com a presença de trabalhadores livres assalariados, todavia, não eram suficientes para formar o capitalismo, necessitando ainda da presença de um mercado para a troca de produtos, visando ao lucro.

Marx elaborou a teoria da mais-valia para explicar a origem do lucro, mencionando que o valor da mercadoria era obtido através do cálculo do tempo necessário para produzi-la, e acrescentando que o valor do lucro não era obtido com o valor da mercadoria em si, pois o capitalista poderia ter lucro vendendo exatamente pelo seu valor, do que se extrai que o lucro era obtido com a exploração da força de trabalho, ou seja, o capitalista pagava um valor " $X "$ ao trabalhador pelo dia de trabalho, mas a contraprestação normalmente já era satisfeita em metade do dia, ou seja, "X"/2, portanto, o excedente, que é a outra metade ("X"/2), totalizava o seu lucro, que é advindo do fruto da força de trabalho sem nenhuma contraprestação. Vale citar que a teoria da mais-valia era subdividida: em relativa, quando utilizava o maquinário, e em absoluta, quando era empregada apenas a força de trabalho. ${ }^{13}$

Para manter o sistema capitalista em pleno funcionamento foi necessária a criação de necessidades simbólicas, incutindo na mente das pessoas que elas necessitavam adquirir mais produtos para se sentirem satisfeitas, e essa necessidade foi criada a partir da publicidade, da obsolescência programada e do fetichismo, sendo que, neste último caso, o produto deixa de ser apenas objeto e passa a ter vida independente, fazendo parte da construção da identidade pessoal de cada indivíduo, o qual passa a se sentir fora do seu meio se não adquire determinado produto.

É interessante mencionar que a sociedade de consumo de massa foi criada por Henry Ford, no sistema fordista, pois a partir do excedente produzido ele precisava de consumidores, e foi neste momento que ele decidiu transformar os seus operários em consumidores, diminuindo o horário de trabalho e aumentando os seus salários. ${ }^{14}$

O capitalismo se move e se reinventa a partir das crises, que nada mais são do que oscilações na economia, no sistema financeiro. A teoria econômica não possui uma definição definitiva sobre a origem das crises, devido à

\footnotetext{
11 Ibidem, p. 392.

12 Ibidem, p. 261-284.

${ }^{13}$ NETTO, José Paulo. O Leitor de Marx. Rio de Janeiro: Civilização Brasileira, 2012, p. 277-310.

${ }^{14}$ ARAÚJO, Adriane Reis de. O Assédio Moral Organizacional. São Paulo: LTr, 2012, p. 33-48.
} 
variedade de causas que as provocam e a inexistência de padrão de tempo entre dois eventos.

Para que o presente artigo não reste por demais extenso e cansativo, optamos por trazer somente a classificação de crise exposta por Joseph Schumpeter, na qual ele afirma que os ciclos variam de acordo com a duração do tempo, e são compostos por quatro momentos, quais sejam, o boom, a recessão, a depressão e a recuperação. Normalmente a crise surge exatamente para quebrar o equilíbrio, e isso normalmente decorre de uma inovação no sistema consistente na inserção de um novo bem no mercado, um novo método de produção ou de comercialização de mercadorias, a conquista de novas fontes de matérias-primas ou a transformação da estrutura do mercado vigente. Por fim, ele assegura que a crise é essencial para o desenvolvimento do capitalismo, inclusive chamando-a de destruição criativa, uma vez que em razão de determinado distúrbio, no sistema, o capitalismo precisa ser criativo e se reinventar para sobreviver. ${ }^{15}$

O fato é que a crise entrava o desenvolvimento, mas após se reinventar, caminha novamente, e tenta encontrar uma nova direção, ou apenas uma maneira diferente de caminhar para a mesma direção:

Os movimentos contrários não apenas entravam o desenvolvimento, mas põem-Ihe um fim. Uma grande quantidade de valores é aniquilada; as condições e os pressupostos fundamentais dos planos dos dirigentes do sistema econômico se alteram. O sistema econômico precisa se reanimar antes de poder caminhar de novo para a frente; o seu sistema de valores precisa se reorganizar. E o desenvolvimento que então começa novamente é um novo e não simplesmente a continuação do antigo. É verdade, e experiência nos ensina que ele se moverá numa direção mais ou menos similar à anterior, mas a continuidade do "plano" é interrompida. ${ }^{16}$

O capitalismo já passou por diversas crises, sendo as principais a crise de 1873-1896, conhecida como a "Longa Depressão", momento no qual houve a substituição da indústria ferroviária para uma rede de ferrovias, sendo os países mais atingidos a Inglaterra e os Estados Unidos, ocasionando ainda o surgimento do capitalismo monopolista. ${ }^{17}$

No ano de 1929, ocorreu a crise denominada de "Grande Depressão" em que houve a quebra da Bolsa de Nova York, devido à forte especulação num

\footnotetext{
${ }^{15}$ SCHUMPETER, Joseph Alois. Teoria do Desenvolvimento Econômico: uma investigação sobre lucros, capital, crédito, juro e o ciclo econômico. Tradução: Maria Sílvia Possas. São Paulo: Nova Cultural, 1997, p. 201-237.

${ }^{16}$ SCHUMPETER, Joseph Alois. Teoria do Desenvolvimento Econômico: uma investigação sobre lucros, capital, crédito, juro e o ciclo econômico. Tradução: Maria Sílvia Possas. São Paulo: Nova Cultural, 1997, p. 205.

${ }^{17}$ HARVEY, David. Entrevista: David Harvey fala sobre a Crise do Capitalismo. Extraído do site: http://youtu.be/VOiFVWOeTeo. Acesso em: 11 fev. 2013.
} 
mercado sem regulação, sendo necessário o aumento dos gastos públicos para conter a crise. ${ }^{18}$

Cita-se, ainda, a crise do petróleo, ocorrida nos anos de 1973 e 1979, decorrente da alta dos preços desse recurso natural, fator que levou muitos países a buscar novas fontes de energia. Nessa crise, houve uma junção de estagnação econômica com altas taxas de inflação, o que era contraditório para as políticas keynesianas aplicadas na época, e, como elas não tinham explicação plausível para o acontecimento, foram culpadas pela crise. ${ }^{19}$

Fazendo um parêntese na explanação das crises, como forma de manter unidade e organização de datas, provoca-se a análise do fenômeno da globalização, ocorrida a partir da década de 1970.

A globalização foi criada intencionalmente pelos países formadores do G-7, multinacionais e instituições financeiras, com o objetivo de controlar as forças de trabalho. É importante destacar que os trabalhadores contavam com altos salários e estavam unidos, o que lhes dava uma formidável força de negociação com seus empregadores. ${ }^{20}$

Considerando que essa força de negociação atrapalhava a exploração da mão de obra pelos capitalistas, e, por sua vez, diminuía os seus lucros, era preciso discipliná-la, e a forma encontrada foi a globalização, com a expansão do mercado de trabalho, dando a possibilidade de as empresas e de as indústrias procurarem países em que a mão de obra fosse mais barata, resultando a diminuição da força dos trabalhadores e dos seus salários.

Com a queda dos salários, surgiu um novo problema: a diminuição do poder de compra, prejudicando o capitalismo, que precisava vender seus produtos para manter seus lucros. Foi então que nasceu a solução de concessão de empréstimos aos empregados, mantendo-se o seu poder de compra.

É certo que o empréstimo se trata de valor fictício, e precisa ser pago, e foi exatamente o não pagamento das dívidas que gerou as crises atuais, adiante detalhadas; portanto, a crise atual tem ligação com o poder excessivo do capital e não dos trabalhadores.

Dando continuidade ao comentário acerca das crises, chega-se ao ano de 2000, na crise intitulada de "Estouro da bolha da Internet", na qual as empresas.com atingiram um valor de mercado bem superior ao real, decorrente do crescimento do setor e da especulação. Deve-se acrescentar, ainda, aos motivos dessa crise, os balanços maquiados e os gastos para prevenir o bug do milênio. Tal crise demonstrou a necessidade da revisão da regulamentação do mercado e reorganização das empresas.

No ano de 2008, advém a crise da "Bolha imobiliária americana", oriunda das prestações não quitadas da casa própria, da supervalorização irreal dos

\footnotetext{
${ }^{18}$ Ibidem.

${ }^{19}$ Ibidem.

${ }^{20}$ CAPRA, Frijot. As Conexões Ocultas. São Paulo: Cultrix, 2006, p. 141-167.
} 
imóveis, bem como da emissão de títulos imobiliários para a obtenção de dinheiro com o intuito de se construirem novos imóveis, títulos que inicialmente prometiam o pagamento de juros altíssimos e que, com a crise, perderam o valor, ocasionando a falência dos bancos e das empresas do setor de imóveis.

O grande problema percebido nas duas crises mencionadas foi a ausência de confiança no mecanismo de desencaixe, tanto das fichas simbólicas quanto dos sistemas auferidos exemplificado neste caso pela expansão dos mercados capitalistas, principalmente, através dos sistemas financeiros, sendo que a confiança está "envolvida de uma maneira fundamental com as instituições da modernidade". ${ }^{21}$

O fato é que as máquinas assumiram o controle do mundo, e nem percebemos, pois o mercado global é um verdadeiro autômato, ou seja, é "uma rede de máquinas programadas para agir segundo um único valor ganhar dinheiro por ganhar dinheiro - à exclusão de todos os outros". ${ }^{22}$

Por fim, não há como deixar de citar, ainda: a crise da Grécia, procedente do não pagamento da dívida externa; da crise do Oriente Médio, motivadora de uma onda de revoltas na luta por democracia; da virada neoliberal, na Islândia, um caso praticamente apagado pela mídia, no qual a população, através de plebiscito, não permitiu o avanço da proposta de pagamento da dívida externa deixada pelos bancos falidos e está julgando e condenando os governantes responsáveis por tal crise. ${ }^{23}$

As crises são imprevisíveis, e, atualmente, mais frequentes, globais, rápidas e profundas, exatamente pela compressão do espaço que foi encolhido em razão das novas tecnologias, principalmente da Internet, e também a compressão do tempo, uma vez que o ritmo de vida está cada vez mais rápido. Nos últimos trinta anos, as crises envolveram valores fictícios, ou seja, provenientes de dívidas, e tiveram grande destaque na área urbana, decorrente de investimentos especulativos decorrentes de hipotecas e de habitação. ${ }^{24}$

O fato é que as crises sempre irão existir, porque fazem parte do capitalismo e se percebe a crise, cada vez mais, pelo sucateamento das instituições e das leis de bem-estar social, no desinteresse pela política, na desigualdade e na polarização social crescente, na pobreza extrema, na exclusão de tudo o que não tem valor, nem interesse para a busca de ganhos financeiros, e, por tais motivos, resta imprescindível avaliar os impactos do sistema capitalista sobre o mercado de trabalho e as suas transformações.

\footnotetext{
${ }^{21}$ GIDDENS, Anthony. As Consequências da Modernidade. São Paulo: UNESP, 1991, p. 29.

${ }^{22}$ CAPRA, Frijot. As Conexões Ocultas. São Paulo: Cultrix, 2006, p. 141-167.

${ }^{23}$ Reportagem: O Neoliberalismo na Berlinda. Extraído do site: http://www.cartacapital.com.br/ internacional/o-neoliberalismo-na-berlinda/. Data da reportagem: 13 abr. 2012. Acessado em: 18 nov. 2012.

${ }^{24}$ HARVEY, David. Condição Pós-Moderna: uma pesquisa sobre as origens da mudança cultural. 5. ed., Tradução: Adail Ubirajara Sobral e Maria Stela Gonçalves. São Paulo: Edições Loyola, 1989, p. 257-276.
} 
Antes de adentrar no rol das transformações, será possível discorrer de um limite do capitalismo? Entendemos que os limites do capitalismo estão nos seus próprios elementos essenciais, ou seja, a ausência de recursos naturais impossibilita a transformação da natureza em produto, e, não tendo produto, não tem venda possível e não tem lucro, mas ainda poderia ser sustentada uma venda de produtos virtuais. De qualquer forma, a ausência de produtos concretos já abalaria o sistema capitalista. A ausência da propriedade privada também afetaria o capitalismo, pois não haveria mais a divisão entre proprietários dos bens de produção e da força de trabalho, impossibilitando a exploração do trabalho do homem. A ausência do trabalhador também colocaria limites no capitalismo, eis que o capital advém da exploração do trabalho alheio. Por fim, a diminuição do consumo também colocaria limites no capitalismo, eis que haveria a diminuição de mercado e lucros.

A própria sociedade, na conscientização de que o sistema capitalista, na maioria das vezes, gera desigualdades sociais e prejuízos advindos da degradação da natureza e da exploração do trabalho, poderia colocar um limite no sistema capitalista, tornando-o mais sustentável.

De qualquer forma, não se pode subestimar a ética do capitalismo, o qual contribuiu para grandes realizações:

Embora o capitalismo com frequência seja visto como um sistema que só funciona com base na ganância de todos, o funcionamento eficiente da economia capitalista depende, na verdade, de poderosos sistemas de valores e normas. Com efeito, conceber o capitalismo como nada mais do que um sistema baseado num conglomerado de comportamento ganancioso é subestimar imensamente a ética do capitalismo, que contribuiu enormemente para suas formidáveis realizações. ${ }^{25}$

Partindo do pressuposto de que seria inimaginável viver fora do sistema capitalista, o questionamento que desponta é se há como amparar a ideia da existência de um capitalismo sustentável, ou seja, que respeite e conviva em harmonia com os direitos socioambientais, e quais mudanças seriam necessárias para tanto.

Entendemos que o primeiro passo para uma real mudança é a escolha correta dos governantes, pois eles podem atuar como um verdadeiro arquiteto de escolhas, que "tem a responsabilidade de organizar o contexto no qual as pessoas tomam decisões", é um verdadeiro empurrão para a escolha certa. ${ }^{26}$

O fato é que a transformação é perene, mas atualmente está tornando a sociedade mais autônoma e consciente de suas decisões transformadoras:

\footnotetext{
${ }^{25}$ SEN, Amartya. Desenvolvimento como Liberdade. Tradução: Laura Teixeira Motta. São Paulo: Companhia das Letras: 2010, p. 334.

${ }^{26}$ THALER, Richard H. Nudge: o empurrão para a escolha certa. Aprimore suas decisões sobre saúde, riqueza e felicidade. Tradução de Marcello Lino. Rio de Janeiro: Elsevier, 2009, p. 3 e 4.
} 
Nos termos de nosso modelo, podemos tomá-lo como indicadores de que um novo modo de transformação social está surgindo lentamente, dotando a sociedade de maior autonomia e controle autoconsciente, crítico e realista sobre o seu próprio destino. Parece ser a próxima mutação no eterno caminho que vai da existência cega, inteiramente objetivada dos povos primitivos, passando pela ingênua megalomania do poder e da razão humana, até a existência totalmente criativa e desperta da sociedade futura esperada, que viva em harmonia com a natureza, reconciliada com os limites do pensamento. Este é o caminho da emancipação história da agência humana. ${ }^{27}$

Enrique Leff, analisando o processo de transformação da sociedade, também defende a inexistência de acidentalidade nas mutações históricas e o poder da crise socioambiental como sustentáculo das decisões conscientes da coletividade para uma mudança significativa da história planetária: ${ }^{28}$

A temporalidade é o ser dos processos e está na essência das coisas. A mudança de época é uma mutação histórica: a mudança, a transformação, já não são acidentes, mas a essência da determinação mutações genéticas, emergência sistêmica, mudança social. A constante é a mudança. Hoje, estar no tempo não se define pela constância do objeto e o fim da história, mas pela mobilização do ser no tempo. O real estoura no limite das inércias de um mundo insustentável, reabrindo os potenciais da história. ${ }^{29}$

Com relação à transformação do mercado de trabalho, muito se replica, desde a flexibilização de direitos trabalhistas até a sua total desregulamentação, ou seja, a ausência total de direitos que protejam o trabalhador, com o intuito de alavancar a economia.

Poder-se-ia, então, afirmar que esse Direito do Trabalho é o causador da crise? Para Aldacy Rachid Coutinho a crise não seria causada pelo Direito do Trabalho, mas pela mudança de paradigma no mercado de trabalho:

(...) Estamos diante de procedimentos de reaproximação com os clientes e concorrentes e da realização das atividades produtivas por meio de rede de subcontratados, terceirizados e alianças empresariais estratégicas. Constantes processos de enxugamento e retirada das gorduras das empresas vêm acompanhadas com um decréscimo da necessidade de trabalho. Para tanto, ao invés de um intervencionismo no mercado,

\footnotetext{
27 SZTOMPKA, Piotr. A Sociologia da Mudança Social. Tradução Pedro Jorgensen Jr. Rio de Janeiro: Civilização Brasileira, 1998, p. 390-391.

${ }^{28}$ MARTINI, Karlla Maria; DINIZ, Patrícia Dittrich Ferreira. O Impacto do Estado de Direito Socioambiental no Princípio da Dignidade. Tese aprovada e apresentada na I Jornada LatinoAmericana de Direito e Meio Ambiente realizada nos dias 22 e 23 de novembro de 2012 na UFSC. Publicada nos anais do evento.

29 LEFF, Enrique. Saber Ambiental: sustentabilidade, racionalidade, complexidade, poder. Tradução de Lúcia Mathilde Endlich Orth. Petrópolis, RJ: Vozes, 2001. p. 415.
} 
realizado pelo direito, com existência de políticas nacionais regulando capital e trabalho, próprias do modelo fordista, o que se propugna é o afastamento do Estado das questões trabalhistas e a sua desregulamentação. O direito do trabalho, assim, não é a causa da crise, mas sofre os efeitos da troca de paradigmas. ${ }^{30}$

Vásquez Vialard, no mesmo sentido, também sustenta que a flexibilização, por si só, não é a chave que solucionará as crises econômicas:

Com razão, Vázquez Vialard adverte que os graves problemas que afligem a maior parte dos países não poderão ser solucionados com simples medidas de caráter jurídico conservadoras do atual estado de coisas, opondo-se à flexibilização, para implementar certas mudanças. A crise impõe a necessidade de mudanças, não do imobilismo. A flexibilização, por si só, não representa a solução, mas cumpre não efetuar essas mudanças apenas 'para que tudo permaneça como está'. ${ }^{31}$

Sobre o tema tão debatido da flexibilização, já comentamos em estudo anterior, afirmando que:

A flexibilização é uma forma elegante de discursar a favor do abandono da proteção ao trabalhador, com um influxo intenso num governo que se rotulava de Governo dos trabalhadores. Será que seremos forçados a entender a precarização dos direitos como uma necessidade imperiosa da sociedade do século XXI? Será possível que o Estado de Bem-Estar Social, realmente, como modelo, perdeu o seu sentido de ser no final do século passado, com o desaparecimento do modelo alternativo ao Capitalismo?

São questões que nos levam a uma forma imperiosa de escolha, quer seja, a partidarização de nossa compreensão do mundo do trabalho, ou pugnamos por uma crescente e inexorável desconstrução dos direitos do trabalhador, ou nos debruçamos sobre as transformações da sociedade e perseguimos, de forma denodada, a construção de um novo Direito, mais protetivo, mais jurídico, menos atávico e mais responsável, não tratando o trabalhador como um "coitadinho" e o empresário como "vilão!, mas compreendendo que entre eles há necessariamente um conflito de interesses, e que o Estado deve ser forte o suficiente para impor as regras que sejam julgadas justas, por toda a sociedade, em benefício dessa mesma sociedade, determinando um esforço hercúleo de reescrever todo o Direito do Trabalho. ${ }^{32}$

${ }^{30}$ COUTINHO, Aldacy Rachid. Direito do Trabalho de Emergência. In Revista da Faculdade de Direito da UFPR, Curitiba, ano 30, $\mathrm{n}^{\circ} 30,1998$, p. 110.

${ }^{31}$ VÁSQUEZ VIALARD, Antônio in Arion Sayão Romita. Flexigurança: a reforma do Mercado de trabalho. São Paulo: LTr, 2008, p. 37.

${ }^{32}$ ARAUJO, Filipe Augusto Lopes de; VILLATORE, Marco Antônio César. O Direito do Trabalho em Tempos de Crises. In: Wilson Ramos Filho. (Org.). Trabalho e Regulação no Estado Constitucional. Curitiba: Juruá, 2011, v. III, p. 81. 
Por fim, deve-se mencionar que qualquer que seja a ótica da transformação, a mesma deve ser sustentável, ou seja, considerando os elementos econômicos, sociais e ambientais, e não é fácil estabelecer os parâmetros das questões sociais no meio laboral, pois devemos aliar a proteção do trabalhador em todos os seus aspectos, desde a manutenção de emprego ou a criação de novas vagas, até a proteção do trabalhador na própria relação de trabalho e a preservação dos seus direitos fundamentais.

\section{DESENVOLVIMENTO SUSTENTÁVEL, REFORMA TRABALHISTA, PRINCÍPIO DA PROTEÇÃO E EFICÁCIA DOS DIREITOS FUNDAMENTAIS DOS TRABALHADORES}

Como apresentado, a transformação do mercado de trabalho deve ser marcada pelo desenvolvimento sustentável, ou seja, considerando em conjunto os aspectos econômico e social. Esta é a perspectiva abordada por Bresser Pereira:

(...) desenvolvimento é um processo de transformação econômica e social, através do qual o crescimento do padrão de vida da população tende a tornar-se automático e autônomo. Trata-se de um processo social global, em que as estruturas econômicas, políticas e sociais de um país sofrem contínuas e profundas transformações... Se o desenvolvimento econômico não trouxer consigo modificações de caráter social e político, se o desenvolvimento político não for a um tempo o resultado e causa de transformações econômicas, será porque de fato não tivemos desenvolvimento. ${ }^{33}$

Se não houver melhoria na condição social da população, destacando-se o papel do mercado de trabalho, não se pode falar em desenvolvimento, mas, no máximo, em crescimento econômico, fator que não é suficiente para caracterizar a sustentabilidade:

(...) o crescimento econômico, tal qual o conhecemos, vem se fundando na preservação de privilégios das elites que satisfazem seu afã de modernização; já o desenvolvimento se caracteriza pelo seu projeto social subjacente. Dispor de recursos para investir está longe de ser condição suficiente para preparar um melhor futuro para a massa da população. Mas quando o projeto social prioriza a efetiva melhoria das condições de vida dessa população, o crescimento se metamorfoseia em desenvolvimento. ${ }^{34}$

Enquanto não houver uma possibilidade ampla e direta da maioria da população em participar e se beneficiar do processo de expansão econômica,

\footnotetext{
${ }^{33}$ BRESSER PEREIRA, Luiz Carlos. Desenvolvimento e Crise no Brasil. 9. ed., São Paulo, Brasiliense, 1980, p. 21.

${ }^{34}$ FURTADO, Celso. Os Desafios da Nova Geração. Artigo extraído da Revista de Economia Política. Vol. 24, nº 4 (96) out./dez. 2004, p. 484.
} 
através da "criação de oportunidades sociais básicas para a equidade e justiça social", pois esta "contribui diretamente para a expansão das capacidades humanas e de qualidade de vida", não se poderá raciocinar em desenvolvimento efetivo. $^{35}$

Para fundamentar o desenvolvimento sustentável, principalmente no seu aspecto social, devemo-nos utilizar do princípio da proteção, o qual servirá de orientação para defender a inaplicabilidade da flexibilização e, mais ainda, da desregulamentação dos direitos de proteção ao trabalhador, evitando a precarização do trabalho humano:

Há que ser interpretado o princípio protetor, então, como cumpridor de relevante função no Direito do Trabalho brasileiro, uma vez que reafirmando o nobre ideal da dignidade humana, não admite que a interpretação e a solução de conflitos de regras jurídicas, qualquer que seja a sua natureza, preste-se à precarização do trabalho humano e à diminuição do patrimônio do trabalhador hipossuficiente. ${ }^{36}$

É importante mencionar que qualquer transformação, no mercado de trabalho, principalmente quando o intuito é alavancar a economia, deve se dar de forma equilibrada, protegendo o trabalhador, tanto quanto à manutenção de seu emprego e das vagas de trabalho, como das suas relações de trabalho:

(...) o direito pode adotar posições de reconhecimento, de anulação, de canalização ou de transformação de suas tendências. No primeiro caso (reconhecimento), o direito reconhece através de suas normas a nova realidade social, declarando a sua legitimidade e, às vezes, criando instrumentos jurídicos que consolidam a mudança. No segundo caso (anulação), o sistema jurídico opõe-se a mudança, ignorando-a ou mesmo aplicando sanções contra determinadas inovações. No terceiro caso (canalização), o direito tenta limitar o impacto de uma mudança ou alterar os seus efeitos, através de reformas que satisfazem parcialmente as reivindicações sociais. No último caso (transformação), o direito assume um papel particularmente ativo: tenta provocar uma mudança na realidade social por meio de reformas graduais e lentas (transição) ou mesmo radicais e rápidas (revolução). ${ }^{37}$

É preciso entender as mutações ocorridas na sociedade para escolher o melhor caminho a seguir, indicando-se que as alterações mais relevantes foram a globalização da economia e a revolução científica e tecnológica, surgindo agora a empresa de $3^{\circ}$ tipo:

\footnotetext{
${ }^{35}$ SEN, Amartya. Desenvolvimento como Liberdade. Tradução: Laura Teixeira Motta. São Paulo: Companhia das Letras: 2010, p. 190-191.

${ }^{36}$ HOFFMANN, Fernando. O Princípio da Proteção ao Trabalhador e a Atualidade Brasileira. São Paulo: LTr, 2003, p. 214.

37 SABADELL, Ana Lúcia. Manual de Sociologia Jurídica: introdução a uma leitura externa do direito. 4. ed., São Paulo: Editora Revista dos Tribunais, 2008, p. 107-108.
} 
(...) que atua no âmbito de uma economia mundializada, dentro de sistemas industriais cada vez mais complexos e interligados, sob a influência de tecnologias cada vez mais sofisticadas que causam a desestabilização dos antigos equilíbrios, ameaçam os mercados cativos e geram desempregos. ${ }^{38}$

Em outra oportunidade, em Congresso Internacional abordando especificadamente sobre a crise econômica e suas influências no mundo do trabalho, abordamos o seguinte:

a saída para a manutenção de empregos em época de crise começa com a boa vontade dos Estados ao diminuir encargos sociais, mas não somente isso, pois devemos também prover àqueles que percam o emprego, com aumento de parcelas de seguro-desemprego, pois as empresas terão maior dificuldade de contratação de novos trabalhadores em um período maior que o normal. ${ }^{39}$

O princípio da proteção é orientador do ordenamento jurídico trabalhista brasileiro e, portanto, deve ser analisado tanto no ambiente legislativo quanto judicial, e, neste último, cabe ao julgador a sensibilidade de analisar as transformações sociais e de decidir de forma equilibrada, aliando a proteção do trabalhador e as demais formas de desenvolvimento:

Esse julgador sensível, - em sintonia com o sofrimento, alegria e anseio da sociedade para a qual trabalha -, faz-me lembrar de um hexagrama que entre os chineses é sinônimo de paz e que é formado por três linhas inteiras sobre três interrompidas: simboliza o masculino que sustenta o feminino, o animus e a anima. Assim, esse símbolo da convivência do Yin e do Yang reflete um milenar sistema filosófico-religioso, que reconhece tanto as diferenças de gênero, como a respectiva coexistência.

Essas configurações arquetípicas podem transmitir a todos, juízes ou não, alento para empreender um esforço interno, que objetiva o diálogo e a conciliação de opostos. E todo o esforço será pouco, porque, como vimos, é extremamente árduo para a consciência - a qual muitas vezes desliza para um padrão de comando (patriarcal) ou de prazer (matriarcal) - , permanecer no estado de alteridade. ${ }^{40}$

Para Leonardo de Gênova, o princípio da proteção pode ser aplicado pela regra in dubio pro operario, da norma mais favorável ou da condição mais benéfica, tendo como conceito ser:

\footnotetext{
${ }^{38}$ ROMITA, Arion Sayão. Direitos Fundamentais nas Relações de Trabalho. 3. ed., São Paulo: LTr, 2009 , p. 225.

${ }^{39}$ VILLATORE, Marco Antônio César; BOSKOVIC, Alessandra Barichello. Crise Econômica: aspectos econômicos e sociais. In: André Jobim de Azevedo; Marco Antônio César Villatore. (Org.). Direito do Trabalho - XIV Jornadas Luso-hispano-brasileiras - Anais. Curitiba: Juruá, 2010, p. 76.

${ }^{40}$ PRADO, Lídia Reis de Almeida. O Juiz e a Emoção: aspectos da lógica judicial. 4. ed., Campinas, SP: Millennium, 2008, p. 103.
} 
(...) basilar, a raiz, a viga mestre, o núcleo do direito do trabalho, sendo que o fundamento da proteção está ligado diretamente com a sua própria existência, pois sem ela não haveria razão de ter uma ciência própria, consolidando normas, doutrinas e jurisprudências próprias. ${ }^{41}$

Já para Mauricio Godinho Delgado, o princípio da proteção não possui aplicação indiscriminada, principalmente quando confrontado com princípios exteriores ao Direito do Trabalho, como os da proporcionalidade, razoabilidade e do não enriquecimento sem causa, sendo tal princípio "uma teia de proteção à parte hipossuficiente na relação empregatícia - o obreiro - visando retificar (ou atenuar), no plano jurídico, o desequilíbrio inerente ao plano fático do contrato de trabalho". ${ }^{42}$

Deve-se citar, ainda, o posicionamento de Paulo Ricardo Schier, que destaca os princípios como fundamento da ordem jurídica justa, sendo que o julgador no caso concreto obterá a justiça através da relação de ponderação dos princípios, rompendo "com a interpretação e aplicação formalista e positivista do Direito, pois o problema de realização da ordem jurídica deixa de tomar um exclusivo comprometimento com as questões de validade $e$ vigência e passa a assumir, mediante a ponderação, a dimensão da relação de justo/injusto do caso concreto". ${ }^{43}$

É exatamente em razão da aplicação do princípio da proteção, explicitado e demonstrado anteriormente, que não se pode aceitar a ideia de flexibilização ou desregulamentação do Direito do Trabalho, pois tais medidas não significam "aumento de empregos e segurança jurídica nas negociações coletivas, pelo contrário, aumentará o trabalho precário e enfraquecimento dos sindicatos". ${ }^{44}$

Vale citar o entendimento de Leonardo de Gênova, correlacionando o princípio da proteção com o sistema econômico:

(...) o princípio da proteção tem como um dos fundamentos a dignidade do trabalhador; dessa forma, é justificável o seu valor. Por outro lado, a flexibilização que degrada o direito do empregado não possui valor-fonte de dignidade humana, pelo contrário, é um mecanismo econômico (fenômeno) criado por um sistema político-econômico (liberalismo), sendo que esse mesmo sistema influenciou o surgimento do direito do trabalho para coibir os seus abusos. ${ }^{45}$

\footnotetext{
${ }^{41}$ GÊNOVA, Leonardo de. O Princípio da Proteção no Século XXI: os novos desafios do trabalhador brasileiro. São Paulo: LTr, 2009, p. 29.

${ }^{42}$ DELGADO, Mauricio Godinho. Princípio de Direito Individual e Coletivo do Trabalho. 2. ed., São Paulo: LTr, 2004, p. 82.

${ }^{43}$ SCHIER, Paulo Ricardo. Filtragem Constitucional: construindo uma nova dogmática jurídica. Porto Alegre: Sergio Antônio Fabris Editor, 1999, p. 131.

${ }^{44}$ GÊNOVA, Leonardo de. O Princípio da Proteção no Século XXI: os novos desafios do trabalhador brasileiro. São Paulo: LTr, 2009, p. 54.

${ }^{45}$ Ibidem, p. 53.
} 
Qualquer que seja a transformação ocorrida no mercado de trabalho, seja através da desregulamentação, flexibilização ou reforma trabalhista, deve preservar a eficácia dos direitos fundamentais dos trabalhadores, ou seja, o foco deve ser sempre o ser humano e a sua dignidade.

Resta interessante citar que a Constituição Francesa de 1973, ao tratar dos direitos fundamentais, elencou a felicidade comum, e, por consequência, o bem-estar dos cidadãos como direito fundamental, e, com certeza, isso somente será possível com a preservação da dignidade do ser humano, principalmente, através da criação e da manutenção de postos de trabalho sustentáveis, ou seja, em que o homem possa extrair o sustento para si e para a sua família de forma digna, com a preservação de seus direitos fundamentais.

É certo que deve haver uma ponderação, um equilíbrio entre os direitos fundamentais do trabalhador e a necessidade de uma reforma trabalhista, mesmo porque tais direitos não são absolutos e "podem sofrer limitações, mas isso somente pode ocorrer desde que haja uma justificativa plausível para o estabelecimento das respectivas restrições, e, ainda, somente depois de uma ponderação entre os direitos eventualmente conflitantes". ${ }^{46}$

O fato é que em qualquer transformação pensada para o mercado de trabalho sempre haverá, de um lado, direitos do empregado, e, de outro, bens do empregador, ambos constitucionalmente garantidos, sempre ressaltando não se poder falar apenas em empregado, muito menos tratá-lo como mercadoria, como mais um número em meio a lucros e prejuízos, sendo preciso entender que o trabalhador deve ser analisado como um cidadão, detentor de um meio social, com família e dignidade, e tudo deve ser considerado em qualquer mudança. ${ }^{47}$

No fundo, todos os direitos fundamentais são de certa forma relacionados com o princípio da dignidade da pessoa humana, mesmo que indiretamente e com intensidades diferenciadas; por fim, "em cada direito fundamental se faz presente um conteúdo ou, pelo menos, alguma projeção da dignidade da pessoa". ${ }^{48}$

A ideia do atual Estado Democrático de Direito deve ser repensada de forma flexível, pois homens do século $X X$ não podem permanecer presos a ditames do século XVIII. É preciso eliminar a rigidez formal, fazer prevalecer a supremacia da vontade do povo, bem como preservar a liberdade e a igualdade; dessa forma, "a democracia deixa de ser um ideal utópico para se converter na expressão concreta de uma ordem social justa". ${ }^{4}$

\footnotetext{
${ }^{46}$ AMARAL, Júlio Ricardo de Paula. Eficácia dos Direitos Fundamentais nas Relações Trabalhistas. São Paulo: LTr, 2007, p. 51.

${ }^{47}$ Ibidem, p. 80-85.

${ }^{48}$ SARLET, Ingo Wolfgang. Dignidade da Pessoa Humana e Direitos Fundamentais na Constituição Federal de 1988. 9. ed., Porto Alegre: Livraria do Advogado Editora, 2012, p. 101.

49 DALLARI, Dalmo de Abreu. Elementos da Teoria Geral do Estado. 28. ed., São Paulo: Saraiva, 2009, p. 307-314. In DINIZ, Patrícia Dittrich Ferreira. O Papel do Poder Judiciário na
} 
Em razão do exposto, extrai-se que qualquer que seja a reforma trabalhista pensada para determinada sociedade, deve ela ser construída com base no princípio da proteção e no desenvolvimento sustentável, não se admitindo mais que sejam considerados apenas o desenvolvimento econômico, em detrimento das suas demais formas.

\section{REFORMA TRABALHISTA NA ITÁLIA E UM COMPARATIVO COM O ORDENAMENTO JURÍDICO BRASILEIRO}

A prioridade do governo de Mário Monti foi a reforma do mercado de trabalho italiano, com base no modelo dinamarquês, da flexisegurança, gerador de maior segurança financeira sem prejudicar o mercado.

O principal objetivo da reforma foi a alteração do artigo 18 do Estatuto dos Trabalhadores (Lei $n^{\circ}$ 300/1970), o qual se refere à forma de dispensa dos empregados, efetivada pela Lei $n^{\circ}$ 92/2012. Destaca-se que o objetivo de tal reforma é restaurar a confiança dos investidores.

Para que se possa entender toda a discussão da reforma trabalhista, na Itália, não se pode deixar de citar o entendimento do PDL - Partido do Povo da Liberdade -, liderado por Silvio Berlusconi, e que pedia mais flexibilidade para os contratos temporários, e do PD - Partido Democrático -, exigindo uma solução para os milhares de trabalhadores que se encontram numa espécie de limbo trabalhista, ou seja, nem aposentados, nem desempregados, em face da reforma do sistema de aposentadorias, adotada em dezembro.

De acordo com Antonio Vallebona, toda reforma legislativa é complicada, pois movimenta interesses de diversos grupos, inclusive muitos dos quais não serão beneficiados com eventuais medidas. De toda a sorte, para que a reforma legislativa seja eficiente e justa, é preciso analisar o interesse geral, e tal fato nem sempre é realizado pelo legislador, influenciado que é, muitas vezes, por outros interesses e jogos políticos. ${ }^{50}$

Somente um legislador, um jurista sério, consegue com paciência e perseverança realizar a construção de um sistema jurídico justo que venha a colocar o ser humano e a sua dignidade em primeiro lugar. ${ }^{51}$

A reforma trabalhista italiana apresenta novidades importantes acerca dos benefícios previdenciários, mas não traz muitas mudanças nas relações de trabalho, realizando apenas manutenção robusta de certas instituições no sistema atual. ${ }^{52}$

A qualidade das normas reformadoras é razoável, mas estas são em número elevado e algumas tecnicamente muito complexas, dificultando a

Busca da Felicidade. Artigo apresentado no III Congresso Brasileiro de Sociologia do Direito realizado nos dias 25 a 27 de novembro de 2012 na UFPR.

${ }^{50}$ VALLEBONA, Antonio. La Riforma del Lavoro 2012. Itália: G. Giappichelli Editore, 2012, p. 1-6.

${ }^{51}$ Ibidem, p. 1-6.

52 Ibidem, p. 1-6. 
aplicação da lei. Vale destacar que a reforma foi mais leve do que o seu projeto e não agradou nem sindicatos, nem organizações empresariais. ${ }^{53}$

Já comentamos, em outro estudo, sobre uma série de reformas ocorridas logo após a crise de 2008:

Logo após o início da crise econômica, no segundo semestre de 2008, vários países iniciaram uma série de políticas para manutenção de empregos e para preparar a sociedade contra a crise eminente que se avizinhava.

A Itália foi prodigiosa, nesse campo, pois já em 28 de janeiro de 2009 foi publicada, na Gazeta Oficial, a Lei $\mathrm{n}^{\circ}$ 2, com "medidas urgentes para sustentar a família, trabalho, emprego e empresa e para redesenhar uma anticrise em quadro estratégico nacional".

No seu artigo $1^{\circ}$, a referida legislação estabeleceu o pagamento um bônus extraordinário, entre duzentos e mil euros, para famílias, aposentados e aquelas pessoas não autosuficientes.

Cerca de metade da supracitada Lei $n^{0} 2$, de 2009, estabelece regras sobre mutuários de primeira casa, empréstimos, diminuições de taxas, dentre outros fatores para não desaquecer a economia italiana.

O artigo 16 determina uma série de reduções dos custos administrativos devidos pelas empresas, em cerca de um terço, justamente para fomentar uma manutenção de empregos, além de medidas de simplificação para as famílias e para as empresas.

O artigo 17 estabelece incentivos para o retorno, à Itália, de docentes e de pesquisadores científicos residentes no exterior, que tenham atividade acadêmica por, no mínimo, dois anos contínuos em centros de pesquisa pública ou privada em Universidades de outros Estados.

No Título III da Lei $n^{\circ} 2$, de 2009, há previsão de um redesenho em função anticrise do quadro estratégico nacional, com proteção do capital humano. É instituído um fundo social para emprego e qualificação junto ao Ministério do Trabalho, da Saúde e de Política Social.

O artigo 19 da supracitada legislação estabelece uma ideia de extensão de instrumentos de tutela de renda, em caso de suspensão do trabalho ou de desemprego, além de concessão de amortizadores sociais e a instituição do fundo de sustento para a ocupação e empreendedorismo juvenil.

Outra legislação importante italiana, publicada em 11 de abril de 2009, é a Lei $n^{\circ} 33$, sobre "medidas urgentes para sustentação dos setores industriais em crise", tendo incentivos para aquisição de veículos ecológicos, menos poluentes, além de detração para aquisição de móveis e eletrodomésticos.

O artigo $7^{\circ}$ dessa legislação prevê derrogação da denominada "Caixa de Integração", que é um amortizador social, em virtude do qual o trabalhador tem o seu contrato de trabalho suspenso e a sua

\footnotetext{
${ }^{53}$ Ibidem, p. 1-6.
} 
remuneração é paga por um ente público, quer seja, o Instituto Nacional de Previdência Social (INPS).

O Estado italiano financiou esse instituto com 8 bilhões de euros e estendeu o apoio a todas as empresas - pequenas, médias e grandes -, enquanto anteriormente a sua utilização tinha limites. ${ }^{54}$

Passamos a analisar alguns pontos importantes da referida reforma trabalhista, iniciando pelo artigo 18 do Estatuto dos Trabalhadores (Lei $\mathrm{n}^{\circ}$ 300/1970).

Resta importante mencionar que, antes desta reforma, a dispensa sem justa causa ensejava o pagamento de indenização ao trabalhador, acrescido do direito de reintegração, sendo que a aplicação da norma era direcionada unicamente para empresas com mais de quinze empregados e não havia obrigatoriedade de comunicação dos motivos, a não ser quando solicitado pelo empregado. É bom lembrar que a reforma trabalhista italiana diferencia os tipos de dispensa em: econômica, disciplinar e discriminatória/proibida.

Na dispensa sem justa causa por motivo econômico, o trabalhador possui direito à reintegração quando restar comprovada a ausência de motivação, e, possui direito à indenização quando tal motivação for ilegal, ou seja, não corresponder à realidade.

Nesta forma de dispensa, a conciliação é obrigatória, devendo o empregador informar o motivo da dispensa, indicando possíveis medidas com o intuito de obter uma recolocação do trabalhador no mercado de trabalho. Caso a conciliação resulte negativa, o Juiz sopesará a conduta das partes para determinar a medida dos benefícios da compensação, e, caso resulte positiva, o trabalhador terá direito ao ASpl - Seguro Social para o Emprego -, com a finalidade de promover a recolocação no mercado.

Quanto à dispensa na modalidade disciplinar, a ocorrência de ausência de motivo ou ilegalidade do mesmo concede ao Juiz a opção pela reintegração quando tal possibilidade for prevista em contrato coletivo nacional ou em código disciplinar, sendo que na ausência destes, cabe apenas indenização.

Por fim, no que concerne à dispensa na modalidade discriminatória/ proibida, ela concretizar-se-á quando a motivação for em razão de política, religião, raça, língua ou sexo, sendo que, neste caso, a reintegração ocorre de forma automática, e na impossibilidade desta, será realizado o pagamento de indenização, não podendo ser inferior a cinco meses.

Tal forma de dispensa não é novidade legislativa, e pode ocorrer de forma específica quando é contígua ao casamento, em caso de maternidade, bem como por razões ilegais, orais ou inválidas, como as citadas anteriormente, sendo indiferente o conhecimento de tais eventos pelo empregador.

\footnotetext{
${ }^{54}$ VILLATORE, Marco Antônio César; PETRUCCI, Fabio. Crise Econômica e Direito do Trabalho Direito de Emergência da Itália. In: $49^{\circ}$ Congresso Brasileiro de Direito do Trabalho, 2009, São Paulo. Jornal do $49^{\circ}$ Congresso Brasileiro de Direito do Trabalho. São Paulo: LTr, 2009. p. 17-18.
} 
Nesta forma de dispensa, há uma questão interessante em relação ao ônus da prova, sendo que no caso da discriminação, por ser uma obrigação de não fazer, tal ônus é do empregado, e se o mesmo opuser elementos de presunção de prova relevantes, a ponto de colocar em cheque o princípio constitucional de igualdade de defesas no processo, neste momento pode ocorrer a inversão do ônus da prova, e, se, nesta demonstração, o empregador também apresentar provas proeminentes, há possibilidade de restauração da divisão do ônus probatório na forma original.

É importante salientar que a justificação correta da dispensa não exclui por definição a natureza discriminatória ou o motivo ilícito, sendo que a sua retirada também não enseja tais elementos de forma automática.

Não se pode deixar de diferenciar a justa causa do ordenamento jurídico brasileiro com a dispensa justificada do ordenamento jurídico italiano, sendo que esta última ocorre somente quando há menor gravidade no inadimplemento do trabalhador, não tendo qualquer relação com aquela, a qual se caracteriza através da falta grave do empregado.

Um ponto importante da reforma é que, agora, a comunicação dos motivos da dispensa é obrigatória e não pode ser modificada.

Outro aspecto importante é que após a reforma ocorre a imediata extinção do contrato de trabalho, no momento da solicitação da indenização substitutiva da reintegração, afastando a interpretação de que no silêncio da lei poderia se supor que tal contrato persistia até o pagamento da indenização, ensejando o lucro imoral do trabalhador, que já havia revelado o seu anseio de não retornar ao trabalho.

Há contratos de trabalho que prescindem de justificação, quais sejam, os dos dirigentes sindicais, trabalhadores aposentados, no final do período de aprendizagem, domésticos e atletas profissionais.

As regras de dispensa aqui mencionadas, após a reforma, podem ser aplicadas a todas as empresas, exceto quando isso foi realizado por motivo econômico, por razões relacionadas com a atividade produtiva, organização do trabalho e bom funcionamento do mesmo, sendo que, nestes casos, somente se aplica a empresas com mais de quinze empregados.

Com relação à referida aplicação da norma de dispensa, o autor Antônio Vallebona entende que a exclusão das empresas menores é absurda, eis que todos os contratos de trabalho devem ser resguardados, e, portanto, provavelmente, tal dispositivo normativo passará por interpretação constitucional ou intervenção da Corte constitucional. ${ }^{55}$

Outra alteração a ser citada foi a da redução do prazo de decadência para a impugnação judicial da dispensa, reduzida de duzentos e setenta dias para cento e oitenta dias, sendo que tal norma se aplica somente para as

${ }^{55}$ VALLEBONA, Antonio. La Riforma del Lavoro 2012. Itália: G. Giappichelli Editore, 2012, p. 44. 
dispensas avisadas após a entrada em vigor da nova lei. Destaca-se que tal prazo tem aplicação ampla, inclusive nas dispensas coletivas, com exceção na dispensa ineficaz por vício de forma.

Somente para ressaltar, tal prazo pode ser proposto na defesa, não podendo ser revelado de ofício, e a apresentação de impugnação judicial extemporânea enseja a decadência do pedido e consequentemente impede a sua análise.

Com relação à possibilidade de retratação da dispensa, deve-se mencionar que, antes da reforma trabalhista, não existia disposição expressa acerca do referido tema, mas somente jurisprudência entendendo que tal retratação necessitava da aceitação do trabalhador, fato que não excluía o direito ao ressarcimento do dano pela dispensa ilegal, exceto nos casos em que o contrato de trabalho permanecia sem solução de continuidade. Caso o trabalhador rejeitasse tal retratação, o seu direito ao ressarcimento pelo dano era excluído no período posterior à proposta de retratação.

Com a reforma, tal tema foi disciplinado de forma expressa com a previsão de possibilidade de retratação da dispensa, devendo ocorrer no prazo de quinze dias da comunicação ao empregador da impugnação e tendo como consequência a restauração do contrato sem solução de continuidade, cabendo ao trabalhador a retribuição pelo período antecedente à retratação.

Aluda-se que a retratação deve ser formalizada por escrito, sendo um direito potestativo do empregador, sem necessidade de aceitação do empregado, com aplicação restrita aos contratos disciplinados pelo artigo 18 do Estatuto dos Trabalhadores (Lei $n^{\circ}$ 300/1970), com o escopo de evitar a conduta especulativa do trabalhador.

A reforma ainda tratou da questão da renúncia em branco e da resolução consensual, eis que antes da alteração legislativa o documento respectivo não era escrito e não tinha data. A Lei no 188/2007 disciplinou o assunto, alterando a formalização da renúncia em branco, determinando a sua forma escrita, necessidade de data e da validade de quinze dias a partir da data aposta, entretanto, tal lei foi revogada sob o fundamento, no ano de 2008 , de que trazia mais problemas do que resolvia, permanecendo a exigência de tal formalidade somente para pedido de demissão de trabalhadoras no período da publicação do matrimônio até um ano após a celebração do casamento, de trabalhadoras gestantes/genitoras (natural, adotivo ou tutelado) por um ano do nascimento ou do ingresso a família, com exclusão das mulheres que prestam serviços a famílias ou domésticas.

Essa regra especial foi estendida à resolução consensual e foi dilatada para três anos no caso de gravidez, adoção e tutela, estabelecendo, para a eficácia da renúncia ou resolução, a convalidação pelo serviço de inspeção da Direção Territorial do Trabalho - DTL -, órgão do Ministério do Trabalho e da Política Social. 
Há alternativas para obter a eficácia das renúncias e resoluções consensuais, quais sejam, a convalidação pela DTL ou em outros locais identificados nos contratos coletivos nacionais ou a aquisição da assinatura do empregado na declaração confirmadora de vontade de extinção do contrato de trabalho enviada ao Centro de Emprego, a qual poderá ser posteriormente identificada para apurar a veracidade da data e autenticidade da manifestação.

De qualquer forma, para evitar a incerteza derivante da suspensão dos efeitos da renúncia ou resolução até a convalidação, o empregador, dentro do prazo de 30 dias dos atos mencionados, deve convidar o trabalhador a efetuar a convalidação, que terá efeito retroativo, devendo tal convite ser por escrito e entregue no domicílio do empregado ou em mãos.

Após tal convite, o empregado tem sete dias para confirmar ou não a convalidação. Em caso positivo ou de não comparecimento o contrato está resolvido, e, em caso negativo, há o retorno ao estado anterior. Destaca-se que o principal objetivo desta norma foi evitar os abusos da renúncia em branco.

Vale citar que a reforma italiana pretende difundir o contrato de trabalho na sua modalidade permanente e desestimular a utilização de contratos a prazo, com o objetivo de aumentar a segurança dos trabalhadores. Determina ações para combater o uso indevido de sistemas de aprendizagem e estágio através da obrigatoriedade do fornecimento de compensação adequada e penalidades para os infratores.

Quanto à complementação salarial ordinária, a Lei não modifica tal instituto, tendo somente o escopo de obter a correta utilização da complementação salarial extraordinária, ou seja, somente para casos extraordinários.

Tais casos restam caracterizados quando sobrevém a suspensão temporária dos contratos de trabalho, em razão de decretação de falência ou recuperação judicial, e, ainda, com a redução das atividades.

Referido benefício pode ser estendido para determinados setores, por um tempo especificado, delimitando um número mínimo de empregados, e estas escolhas podem ser alteradas periodicamente, e, principalmente, não pode servir como substituto da indenização do desemprego, pois não é esta a sua finalidade.

As empresas que não são beneficiadas com essa complementação salarial são obrigadas a realizar uma negociação coletiva, no prazo de seis meses da entrada em vigor desta norma, estabelecendo um fundo de solidariedade bilateral, intersetorial, com a primeira tarefa de fornecer prestações suplentes desta integração, e, eventualmente, prestações integrativas do ASpl - Seguro Social para o Emprego -, sendo que nada impede que tal negociação seja feita por empresas já abrangidas pela integração.

É interessante e positiva a tentativa de universalizar as garantias identificadas no caso de suspensão e redução do trabalho, bem como a delegação aos parceiros sociais para a criação dos fundos de solidariedade, 
aliando os meios públicos e privados, pois tais elementos, quando utilizados com conhecimento e crença, podem ser o novo rumo do sistema de segurança social.

Por fim, o último destaque da reforma trabalhista são as proteções em razão do desemprego, com a supressão total da indenização de mobilidade a partir de 2017, pois este benefício era destinado somente para empregados de empresas específicas, e a introdução do ASpl - Seguro Social para o Emprego -, tem cabimento geral. Não recebem o referido seguro os funcionários públicos com contrato permanente e os trabalhadores agrícolas permanentes ou temporários.

O subsídio tem duração de dois anos para o empregado contribuinte pelo período de um ano, durante os dois anos anteriores ao desemprego, e o legislador não estendeu tal benefício, de forma expressa, aos empregados dispensados por justa causa.

Restou criado também o mini ASpl - Seguro Social para o Emprego -, visando a beneficiar o empregado que recolheu apenas treze semanas nos últimos doze anteriores ao desemprego, mas com valores menores.

O trabalhador que deixar de comparecer sem motivo justificado para a convocação, ou recusar sem motivo justo um trabalho, perde o direito ao ASpl - Seguro Social para o Emprego.

O principal objetivo do benefício é a obtenção da reintegração do trabalhador, no mercado de trabalho, a formação profissional por parcerias público-privadas, o controle das finanças públicas, estimular as pessoas a procurar um novo emprego com diligência, bem como simplificar os procedimentos entre a demanda e a oferta de emprego, pela utilização de banco de dados contendo o nome dos desempregados que recebem benefícios e procurar uma forma mais célere de o trabalhador receber a oferta de trabalho, ou seja, através de telefone, celular e e-mail.

Fazendo-se um comparativo com as regras trabalhistas italianas, após a reforma, e com o ordenamento jurídico brasileiro atual, infere-se que o sistema italiano ainda é mais protetivo, inclusive no que se refere às dispensas, eis que aplica de certa forma a Convenção $\mathrm{n}^{\circ} 158$ da OIT, determinando sempre a motivação da dispensa, diferente do Brasil, que exige tal motivação apenas quando se tratar de dispensa por justa causa, nos moldes do artigo 482 da CLT.

Vale citar ainda a Lei brasileira $n^{\circ}$ 9.029/95, com a finalidade de combater a discriminação nas relações de trabalho, principalmente por motivo de sexo, origem, raça, cor, estado civil, situação familiar ou idade; o artigo $7^{\circ}$, XXX da Constituição de 1988 e o artigo 10, II dos Atos das Disposições Constitucionais Transitórias veda a dispensa da empregada gestante.

Podemos observar que, neste aspecto, os dois ordenamentos jurídicos de certo modo se assemelham, quanto às proteções e defesa quanto a eventuais discriminações no trabalho. 
No que se refere ao direito ao seguro-desemprego pode-se concluir também que o ordenamento jurídico italiano é mais protetivo em relação ao brasileiro.

De toda a sorte, entendemos que a reforma trabalhista, na Itália, foi importante para manter os empregos e até criar novas vagas de trabalho, além de dar oportunidades iguais para uma parcela mais ampla dos trabalhadores, portanto, agiu com sustentabilidade, com equilíbrio nas decisões, e priorizando o desenvolvimento econômico, social e ambiental, pois a crise econômica na região é intensa e tal medida é necessária para tentar-se manter a estabilização.

\section{CONSIDERAÇÕES FINAIS}

Partindo do pressuposto que seria inimaginável viver fora do sistema capitalista, o questionamento que desponta é se há como amparar a ideia da existência de um capitalismo sustentável, ou seja, que respeite e conviva em harmonia com os direitos socioambientais, e quais mudanças seriam necessárias para tanto.

Com relação à transformação do mercado de trabalho, muito se replica, atualmente, desde a flexibilização de direitos trabalhistas até a sua total desregulamentação, ou seja, a ausência total de direitos que protejam o trabalhador, com o intuito de alavancar a economia.

De toda a sorte, qualquer que seja a ótica da transformação, a mesma deve ser sustentável, ou seja, considerando os elementos econômicos, sociais e ambientais, não sendo fácil estabelecer os parâmetros das questões sociais no âmbito laboral, pois devemos aliar a proteção do trabalhador em todos os seus aspectos, desde a manutenção de emprego ou a criação de novas vagas, até a sua proteção na própria relação de trabalho.

Para fundamentar o desenvolvimento sustentável, principalmente no seu aspecto social, devemo-nos utilizar do princípio da proteção, que servirá de orientação para defender a inaplicabilidade da flexibilização e, mais ainda, da desregulamentação dos direitos de proteção ao trabalhador, evitando a precarização do trabalho humano.

Qualquer que seja a reforma trabalhista pensada para determinada sociedade, deve esta ser construída com base no princípio da proteção, na preservação dos direitos fundamentais do trabalhador e no desenvolvimento sustentável, não se admitindo que sejam considerados apenas aspectos econômicos, em detrimento das demais formas de desenvolvimento.

No Direito Comparado, foi apresentada a recente reforma trabalhista italiana realizada pela Lei $n^{\circ}$ 92/2012, implicando alterações do Estatuto dos Trabalhadores (Lei $n^{\circ}$ 300/1970), principalmente quanto à extinção do contrato de trabalho (dispensa, renúncia em branco e resolução consensual), retratação da dispensa, complementação salarial ordinária e extraordinária, e, ASpl - Seguro Social para o Emprego -, além de um comparativo com o ordenamento jurídico brasileiro. 
Tal reforma foi necessária exatamente para equilibrar o desenvolvimento econômico e social, na Itália, manter empregos e trazer benefícios, mesmo que menores, para a maior parte dos trabalhadores e não somente para uma pequena parte da sociedade.

Por fim, sempre haverá uma guerra incessante entre a necessidade do alcance cada vez maior de lucros, imposta pelo sistema capitalista, e a necessidade de preservação dos direitos fundamentais dos verdadeiros trabalhadores-cidadãos, fator que incentivará mudanças constantes para a própria manutenção do sistema, que, na sua própria evolução, deverá sempre colocar como ponto chave a existência do ser humano com dignidade.

\section{REFERÊNCIAS BIBLIOGRÁFICAS}

AMARAL, Júlio Ricardo de Paula. Eficácia dos Direitos Fundamentais nas Relações Trabalhistas. São Paulo: LTr, 2007.

ARAÚJO, Adriane Reis de. O Assédio Moral Organizacional. São Paulo: LTr, 2012.

ARAUJO, Filipe Augusto Lopes de; VILLATORE, Marco Antônio César. O Direito do Trabalho em Tempos de Crises. In: Wilson Ramos Filho. (Org.). Trabalho e Regulação no Estado Constitucional. Curitiba: Juruá, 2011, v. III, p. 63-82.

BRESSER PEREIRA, Luiz Carlos. Desenvolvimento e Crise no Brasil. 9. ed., São Paulo: Brasiliense, 1980.

CAPRA, Frijot. As Conexões Ocultas. São Paulo: Cultrix, 2006.

COUTINHO, Aldacy Rachid. Direito do Trabalho de Emergência. In Revista da Faculdade de Direito da UFPR, Curitiba, ano 30, n 30, 1998.

DALLARI, Dalmo de Abreu. Elementos da Teoria Geral do Estado. 28. ed., São Paulo: Saraiva, 2009.

DELGADO, Mauricio Godinho. Princípio de Direito Individual e Coletivo de Trabalho. 2. ed., São Paulo: LTr, 2004.

DINIZ, Patrícia Dittrich Ferreira. O Papel do Poder Judiciário na Busca da Felicidade. Artigo apresentado no III Congresso Brasileiro de Sociologia do Direito realizado nos dias 25 a 27 de novembro de 2012 na UFPR.

FOSTER, John Bellamy. O Conceito de Natureza em Marx: materialismo e natureza. 3. ed., Rio de Janeiro: Civilização Brasileira, 2005.

FURTADO, Celso. Os Desafios da Nova Geração. Artigo extraído da Revista de Economia Política. Vol. 24, no 4 (96) out./dez. 2004.

GÊNOVA, Leonardo de. O Princípio da Proteção no Século XXI: os novos desafios do trabalhador brasileiro. São Paulo: LTr, 2009.

GIDDENS, Anthony. As Consequências da Modernidade. São Paulo: UNESP, 1991.

HARVEY, David. Condição Pós-moderna: uma pesquisa sobre as origens da mudança cultural. 5. ed., Tradução: Adail Ubirajara Sobral e Maria Stela Gonçalves. São Paulo: Edições Loyola, 1989.

. Entrevista: David Harvey fala sobre a Crise do Capitalismo. Extraído do site: http://youtu.be/VOiFVWOeTeo. Acesso em: 11 fev. 2013.

HOFFMANN, Fernando. O Princípio da Proteção ao Trabalhador e a Atualidade Brasileira. São Paulo: LTr, 2003. 
LEFF, Enrique. Saber Ambiental: sustentabilidade, racionalidade, complexidade, poder. Tradução de Lúcia Mathilde Endlich Orth. Petrópolis, RJ: Vozes, 2001.

MARTINI, Karlla Maria; DINIZ, Patrícia Dittrich Ferreira. O Impacto do Estado de Direito Socioambiental no Princípio da Dignidade. Tese aprovada e apresentada na I Jornada Latino-Americana de Direito e Meio Ambiente realizada nos dias 22 e 23 de novembro de 2012 na UFSC. Publicada nos anais do evento.

MARX, Karl. O Capital: crítica da economia política. Livro primeiro. São Paulo: Abril Cultural, 1984.

NETTO, José Paulo. O Leitor de Marx. Rio de Janeiro: Civilização Brasileira, 2012.

PRADO, Lídia Reis de Almeida. O Juiz e a Emoção: aspectos da lógica judicial. 4. ed., Campinas, SP: Millennium, 2008.

Reportagem: O Neoliberalismo na Berlinda. Extraído do site: http://www.cartacapital.com.br/ internacional/o-neoliberalismo-na-berlinda/. Data da reportagem: 13 abr. 2012. Acessado em: 18 nov. 2012.

ROMITA, Arion Sayão. Flexigurança: a reforma do Mercado de trabalho. São Paulo: LTr, 2008.

Direitos Fundamentais nas Relações de Trabalho. 3. ed., São Paulo: LTr, 2009.

SABADELL, Ana Lúcia. Manual de Sociologia Jurídica: introdução a uma leitura externa do direito. 4. ed., São Paulo: Editora Revista dos Tribunais, 2008.

SARLET, Ingo Wolfgang. Dignidade da Pessoa Humana e Direitos Fundamentais na Constituição Federal de 1988. 9. ed., Porto Alegre: Livraria do Advogado Editora, 2012.

SCHIER, Paulo Ricardo. Filtragem Constitucional: construindo uma nova dogmática jurídica. Porto Alegre: Sergio Antônio Fabris Editor, 1999.

SCHUMPETER, Joseph Alois. Teoria do Desenvolvimento Econômico: uma investigação sobre lucros, capital, crédito, juro e o ciclo econômico. Tradução: Maria Sílvia Possas. São Paulo: Nova Cultural, 1997.

SEN, Amartya. Desenvolvimento como Liberdade. Tradução: Laura Teixeira Motta. São Paulo: Companhia das Letras: 2010.

SITE: http://www.cartacapital.com.br/internacional/o-neoliberalismo-na-berlinda/. Acessado em 18 nov. 2012.

SZTOMPKA, Piotr. A Sociologia da Mudança Social. Tradução Pedro Jorgensen Jr. Rio de Janeiro: Civilização Brasileira, 1998.

VALLEBONA, Antonio. La Riforma del Lavoro 2012. Itália: G. Giappichelli Editore, 2012.

VILLATORE, Marco Antônio César; PETRUCCI, Fabio. Crise Econômica e Direito do Trabalho - Direito de Emergência da Itália. In: $49^{\circ}$ Congresso Brasileiro de Direito do Trabalho, 2009, São Paulo. Jornal do $49^{\circ}$ Congresso Brasileiro de Direito do Trabalho. São Paulo: LTr, 2009. p. 17-18.

; BOSKOVIC, Alessandra Barichello. Crise Econômica: aspectos econômicos e sociais. In: André Jobim de Azevedo; Marco Antônio César Villatore. (Org.). Direito do Trabalho - XIV Jornadas Luso-hispano-brasileiras - Anais. Curitiba: Juruá, 2010, p. 49-77.

WEBER, Max. A Ética Protestante e o "espírito" do Capitalismo. Tradução: José Marcos Mariani de Macedo. São Paulo: Companhia das Letras, 2004. 